\title{
DISSECTING ANEURYSM OF THE AORTA, WITH CARDIO- GRAMS SUGGESTIVE OF CARDIAC INFARCTION
}

\author{
BY \\ GEOFFREY. BOURNE AND P. J. W. MILLS \\ From St. Bartholomew's Hospital and the British Postgraduate Medical School \\ Received May 16, 1946
}

Two cases are here described in which the clinical picture was in some respects similar to that of myocardial infarction, and the electrocardiographic changes, although atypical, also suggested this diagnosis. Post-mortem examination showed the presence in each case of a dissecting aneurysm of the aorta, but revealed no evidence of any coronary infarction past or present.

The clinical pictures were suggestive of myocardial infarction in several respects. In each the pain was as severe as that seen in many cases of cardiac infarct, and its position although not typical was compatible with this diagnosis. In Case 1, the pain started in the front of the chest and was transmitted to the back; it also radiated to the upper abdomen. In Case 2, the pain was felt in the neck and through to the back under the scapulæ.

Shortness of breath was not a feature in either case, and was not complained of, apart from the distress naturally present before death. But shortness of breath is by no means constant in all cases of coronary infarction. Shock was a marked feature in both patients at some time; in Case 1 the systolic blood pressure fell to 80, and in Case 2 to $90 \mathrm{~mm}$. In Case 2, pericardial friction developed and was sufficiently loud and characteristic to be demonstrated to students, although it was transient. In Case 1 the cardiogram was very suggestive of posterior infarct, and in Case 2 not only was well-marked S-T deviation present in leads II and IV, but the character of the tracing changed rapidly in two days, after which interval a bundle branch block had appeared.

It is interesting to speculate how these changes might have been produced; tabulation of various possibilities may be useful at this stage, to draw attention to these points in the details of the case reports.

1. Myocardial infarction might doubtless co-exist with a dissecting aneurysm.

2. The infiltration of the blood in the middle coat of the aorta might extend to a point where it influenced the coronary vessels passing through the aorta.

3. The infiltrating blood, in its way around the aortic curve, might stiffen the aorta, changing its normal tensions.

4. A similar process might twist it in the same way as the vessel is sometime twisted in pneumothorax, where cardiographic changes are also known to occur (Master, Dacks, Kalter, and Jaffe, 1937).

5. Finally, the ætiology of dissecting aneurysm is sometimes uncertain, but it seems that some degeneration of the substance of the aortic media may be a causative factor. It is theoretically possible that this degeneration may be acute, and may occur simultaneously in the substance of the heart muscle.

\section{FIRST CASE RePORT}

Case 1. A woman, aged 62, was admitted to hospital on $29 / 8 / 44$ for diabetic symptoms with a six months' history of thirst, polyuria, loss of weight, undue fatigue, and paræsthesiæ in hands and feet. She also gave a history of an attack of very severe epigastric pain after a meal one week before admission; this pain radiated to the back, and was thought to be due to a flatulent dyspepsia although there was no such previous history.

Examination showed signs of recent loss of weight although the patient was still obese. Temperature, pulse, and respiration were normal. The retinal arteries were thickened, but the discs and retinæ were otherwise normal. 
There was a ringing aortic second sound. There was no clinical evidence of a mediastinal syndrome to suggest aneurysm. The B.P. was 220/120. The upper limbs were normal although the patient complained of tinglings in the fingers. The tendon reflexes were present and there was no sensory loss. The knee and ankle jerks were absent in both legs, and there was diminished sensation to pinprick, and impaired sensibility to light touch. Kinæsthetic sensation was present. The plantar reflexes were flexor.

In the urine (sp. gr. 1028), Benedict's solution was reduced to orange and Rothera's and Gerhardt's tests were positive. The fasting blood sugar was $278 \mathrm{mg}$. per 100 c.c. Sugar tolerance curve was typical of diabetes with blood sugar of $362 \mathrm{mg}$. per 100 c.c. two hours after $50 \mathrm{~g}$. of glucose. Blood urea normal. Blood W.R. and Kahn negative. The cerebrospinal fluid was normal, and the W.R. negative.

X-ray of chest (Fig. 1) showed enlargement of left ventricle, aorta unfolded and elongated, with dilatation of the arch. No aortic pulsation. Lung fields clear. A diagnosis of diabetes mellitus with mild peripheral neuritis was made.

The diabetes was controlled by diet and 8 units of insulin b.i.d. and the fasting blood sugar was thus reduced to $120 \mathrm{mg}$. per 100 c.c.

On 2/9/44 (4 days after admission) the patient asked for a bed-pan and while on the pan complained of sudden intense tearing pain in the upper abdomen and middle of chest radiating to the back. She collapsed and became semi-comatose, with Cheyne-Stokes respiration. On examination she was very cold and the blood pressure fell to 80 systolic, the diastolic reading being unobtainable. Morphia was given with some relief of pain. After a few hours she made a gradual recovery, although the pain in the back persisted for the next two or three days, by which time she also had some difficulty in swallowing. A cardiogram taken 12 hours after the attack showed no changes suggestive of a coronary thrombosis (Fig. 2A). 
On this history, especially the persistent pain in the back and the absence of the cardiographic changes of coronary thrombosis, a diagnosis of dissecting aneurysm of the aorta was made. During the next five days the patient's condition improved, the blood pressure gradually rose to 140/80, and the dysphagia disappeared. A further cardiogram (Fig. 2B) taken on 27/9/44 (five days after the attack) strongly suggested a posterior myocardial infarction as shown by a deep Q III and elevated S-T and inverted T, both in lead III. It was then thought that the original diagnosis of dissecting aneurysm was wrong and that a coronary thrombosis must be the cause of the pain and collapse. A further cardiogram (Fig. 2C) still suggested myocardial infarction.

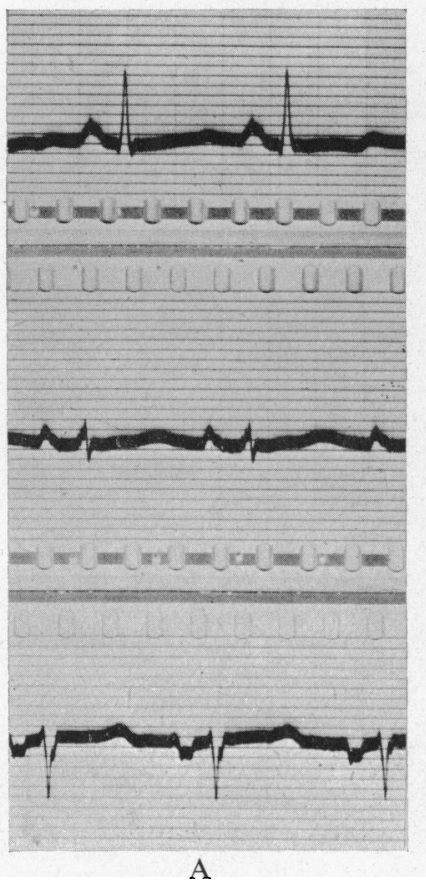

FIG. 2.-Left axis deviation. (A) evidence of myocardial infarct.

(B) 27/9/44. S-T deviation downwards in leads I and II and upwards in III. Deep Q in lead III. T now inverted in lead III.

(C) 11/10/44. Similar to Fig. 2 (B). T wave further inverted in lead I.

On 14/10/44 the patient suddenly had a severe hæmoptysis; she collapsed and rapidly became comatose, the blood pressure falling to 60 systolic. She remained comatose for about three hours and during this time passed a tarry stool and then died. In view of the terminal hæmoptysis and melæna, the original diagnosis of dissecting aneurysm of the aorta was thought to be established, although this made the cardiographic changes difficult to explain.

\section{Post-mortem Examination}

Pleural spaces dry, lungs expanded, two large thoracic dissecting aneurysms, loaded abdominal fat depots, small intestine distended with blood.

Heart and Aorta. Heart: 280 g., valves and chambers normal, coronary arteries atheromatous but nowhere occluded or grossly narrowed. Aorta: ectasia and fatty atheroma of ascending portion, severe calcified atheroma of arch and descending thoracic and abdominal portions. Junction of transverse and descending aorta marked by beginning of a dissecting aneurysm localized to medial wall and bulging into subepicardial portion of left lung $(8 \mathrm{~cm}$. long, $4 \mathrm{~cm}$. wide, $3 \mathrm{~cm}$. outward bulge into lung) (Fig. 3). No obvious primary intimal tear; instead there was a large patch proximally of ulcerated intima covered by laminated clot. Externally, this part of aneurysm was firmly attached to the lung by fibrous adhesions and organized thrombus. It contained a small linear longitudinal external tear through which a probe passed from the aortic lumen direct into upper lobe of left lung, which was torn up by 
hæmorrhage. $10 \mathrm{~cm}$. distal to the isthmus the intima presented a transverse rupture of $1 \mathrm{~cm}$. (Fig. 3) leading into the proximal portion of a second large dissecting aneurysm, bulging anteriorly and laterally into lower lobe of right lung $(8 \mathrm{~cm}$. long, $4 \mathrm{~cm}$. wide, $5 \mathrm{~cm}$. bulge). This was firmly adherent to the lung, and there was no external tear. The left auricle was pushed forwards and the œsophagus compressed anteriorly and to the right (Fig. 4). Blood clot in both aneurysms was lying inside the split medial coat of the aorta. Transverse sections of the abdominal aorta showed two separate incipient aneurysms in the form of hæmatomas of the media (each about $1 \mathrm{~cm}$. in diameter) lying 5 and $9 \mathrm{~cm}$. distal to the coeliac axis (Fig. 5). The overlying intima was intact.

The trachea and bronchi and their branches in both lungs were filled with blood. Lung parenchyma: mixed hæmorrhage and emphysema. Pool of blood in nasopharynx. Stomach: distended with 500 c.c. mixed blood and gastric juice; no peptic ulceration. Intestines: contained blood and tarry material down to rectum. Viscera pale; arteries atherosclerotic.

Death was due to hæmorrhage from rupture of an aortic dissecting aneurysm into the left lung. Blood had entered the air-passages (precipitating an acute emphysema) welled up into nasopharynx and passed down into stomach during patient's terminal coma.

Microscopic Findings. Aorta shows atrophy and diminution in number of medial elastic fibres, fatty degeneration of internal elastic lamina, localized complete medial atrophy underlying some intimal atheromatous plaques, no mucoid or cystic degeneration but marked increase in hyaline and collagen at junction of outer and middle thirds of media (surrounding most internal branches of vasa vasorum) (Fig. 6). It is this part of the middle coat that is split to enclose the hæmatomas and aneurysms. The plane of cleavage in the upper aneurysm is filled with young granulation tissue rich in phagocytes loaded with blood pigment (Fig. 7). The local adventitia shows vasa vasorum cuffed with lymphocytes, histiocytes, and pigment phagocytes. No syphilitic mesaortitis. The upper aneurysm appeared to be the oldest lesion; the outer wall consisted of fibrosing granulation tissue rich in hæmosiderin. 


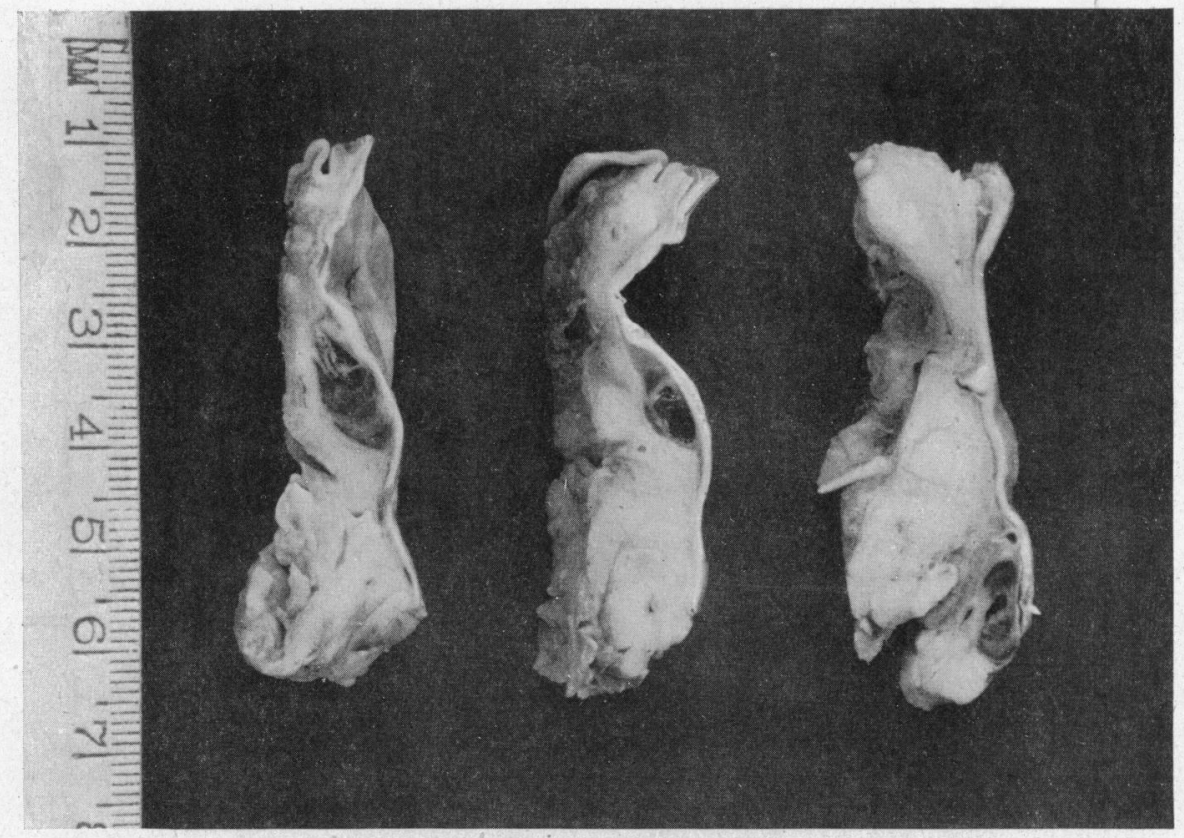

FIG. 5.-Transverse sections of the medial hæmatomas (incipient aneurysms) in the abdominal aorta.

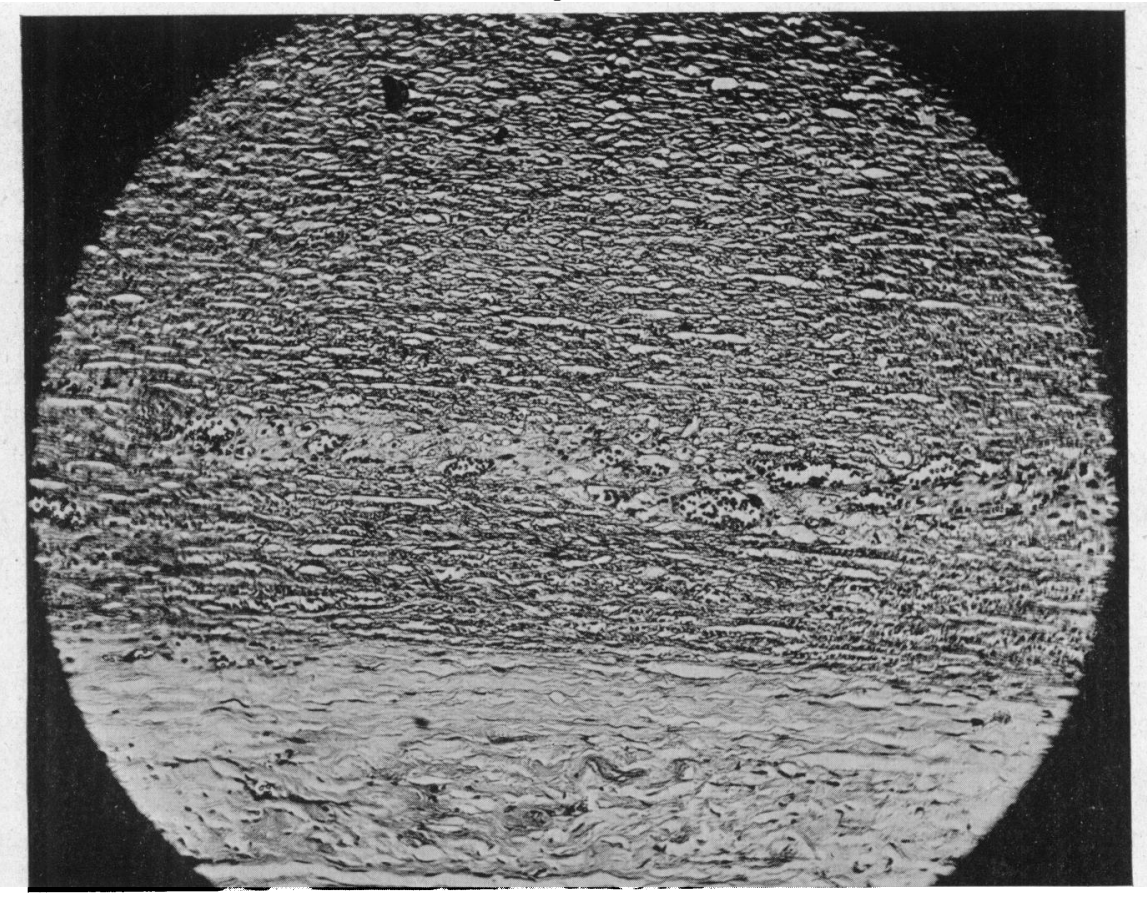

FIG. 6.-Section of thoracic aorta media (iron hæmatoxylin, van Gieson and Verhoef): atrophy of elastic fibres with hyalinization and increased vascularity at the junction of the outer with middle third of the media. Magnification : $\times 97$. 
The heart shows very little increase in interstitial fibrous tissue except for subepicardial pale areas in the left ventricle which consist of ancient acellular collagen.

The sequence of events appears to have been first a chronic degenerative hyalinization of the middle coat of the aorta, secondly acute hæmatoma formation in the media at the junction of middle and outer thirds, thirdly rupture of the underlying intima, and fourthly dissection of the vulnerable media by the inrushing aortic blood with the formation of dissecting aneurysms. In this case there is no doubt that atheroma has played an important role in the localization of the site of primary intimal rupture.

\section{SECOND CASE REPORT}

A housewife, aged 36, had for a period of ten weeks before admission been complaining of pain below both shoulder blades and upon each side of the neck. She suffered from this pain in attacks which would pass off, and they might be associated both with nausea and with giddiness. She was not short of breath in the intervals between the attacks, but noticed some dyspnœa at the time. The original attack occurred while she was ironing, and the pain and discomfort were severe enough to need the attention of a doctor. This attack lasted throughout the day and increased in severity until she vomited in the evening. Since the first attack she had felt what she described as a lump in her throat, which was present all the time and especially noticeable on swallowing.

Five weeks before admission, on getting up in the morning she had a particularly severe attack associated with intense nausea. She recovered, however, and continued up and about, feeling fairly well except for slight recurrent attacks of the nature described above. She had no cough, no pain in the front of the chest, no hæmoptysis nor interference with breathing. Her appetite had been good and there were no other complaints. On the morning of admission she was seized with a more severe attack than she had previously suffered, and was admitted lying flat on a stretcher, intensely cyanosed, with a raised respiration rate and grunting expiration. There was no stridor. She also complained of numbness in the left arm, and kept her eyes closed because of intense vertigo. 
On examination, which was limited in thoroughness by the patient's very distressed condition, the following outstanding points were noticed at this time. There was no orthopnœa. Cyanosis was intense; arterial and venous pulsation in the neck vessels was more than normal. The apex beat was outside the mid-clavicular line and was firm and normal in character. There were no murmurs. There appeared to be some slight diminution in the volume of the respiratory murmur at the right apex, and râles were present over the right chest. In other respects the lungs and pleuræ seemed to be normal. Later in the day the patient became extremely short of breath with increased cyanosis and with stridor. She was very restless. She then spat up a quantity of thick, frothy, unstained sputum, and was given morphia $1 / 6$ th, and atropine $1 / 100$ th of a grain, and oxygen by B.L.B. mask. She improved during the next 48 hours. Two days after admission the increased pulsation was still visible in the neck, the heart sounds were still normal, but in addition a triple friction sound was audible all over the præcordium, and especially in the area between the apex beat and the left sternal border. The blood pressure was $94 / 40$, the heart rate 112 , and the respiration rate 40.

During the day the patient became comatose and died.

The electrocardiogram taken on the day of admission (Fig. 8A) showed flattening of $\mathrm{T} I$ and well-marked S-T deviation downwards in leads I, II, III, and IV. The tracing taken two days later (Fig. 8B) showed the development of a left bundle branch lesion. The X-ray

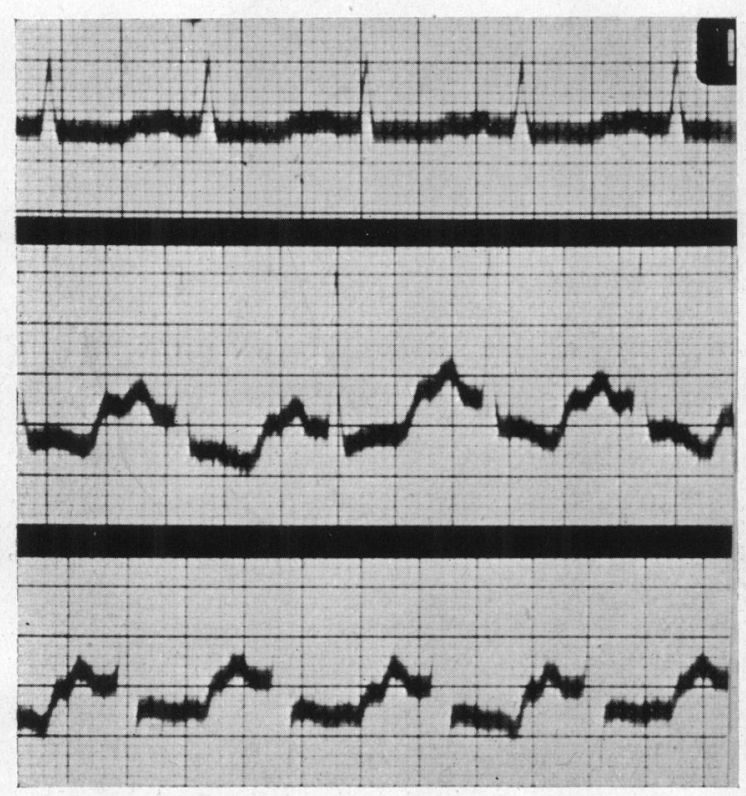

A

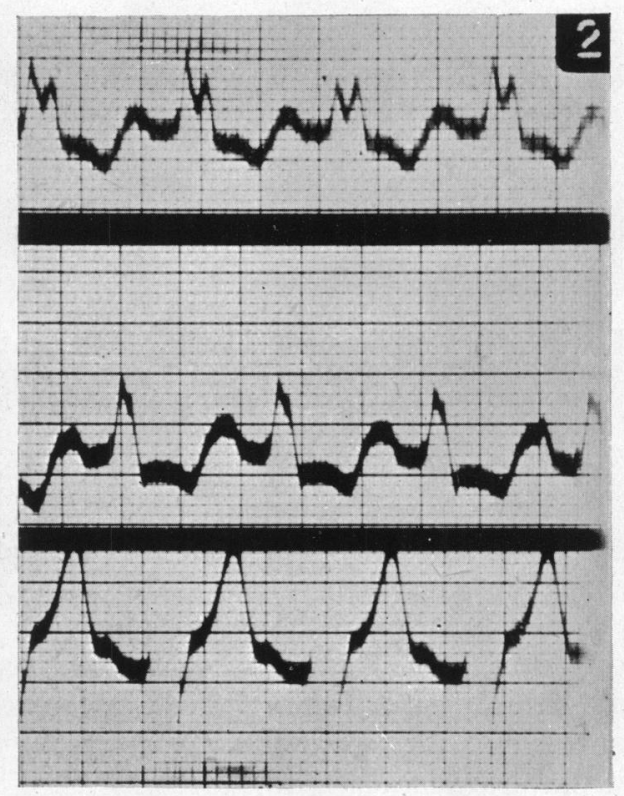

B

FIG. 8.-(A) Taken on day of admission, showing S-T deviation downwards in leads I, II, and III. T flat in lead I. (B) Two days later, showing left bundle branch defect.

film (Fig. 9) showed deviation of the trachea to the right at the level of the sterno-clavicular joints. Behind the left joint was a shadow corresponding to the post-mortem demonstration of an extension of the dissecting aneurysm along the origin of the left subclavian artery. The right lung was less translucent than the left, and the radiologist suggested the possible presence of some scattered consolidation, possibly in relation to an infarct. The right pulmonary artery was very prominent. These radiological differences between the two sides of the chest corresponded to the difference in physical signs. Such change could easily be produced by central mediastinal changes causing interference with the pulmonary arterial or venous systems. The heart showed no radiological evidence of increase in size. 


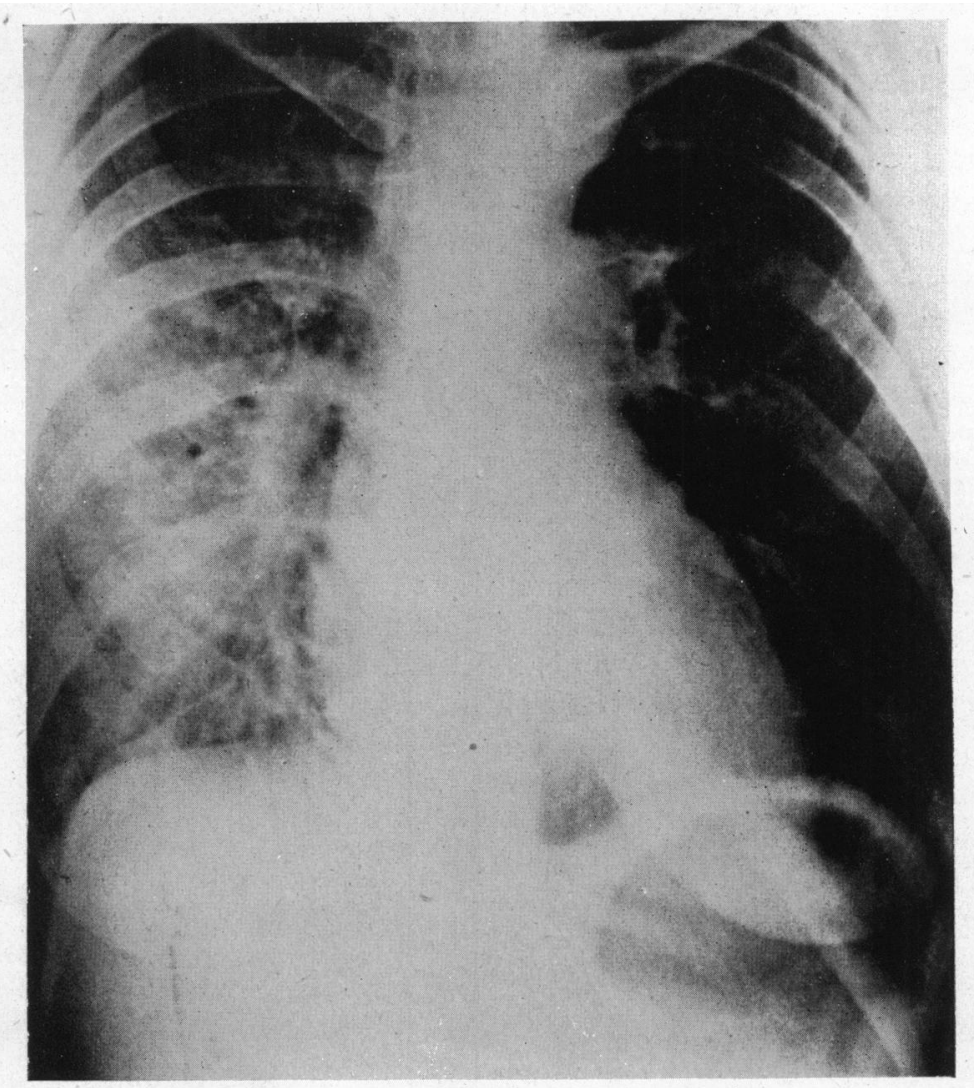

FIG. 9.-Heart within normal limits. Aortic shadow extended to left subclavicular region, corresponding to site of subclavine extension of aneurysm. Right pulmonary artery abnormally prominent. Increased vascularity of middle and lower zones of right lung.

\section{Post-mortem Examination}

The body was well nourished. Head and neck were normal.

Thorax. On drawing forward the mediastinal contents the aorta was seen as a thickened, shaggy-looking structure. The thickening was due to a dissecting aneurysm, which had completely stripped the outer from the inner coats at the level of the ascending portion of the aorta. The dissecting blood formed a larger mass of organizing clot, probably six weeks old; this mass extended proximally to within half an inch of the aortic valves and also along an inch of the left subclavian artery; a longitudinal slit, one-quarter of an inch in length with sharp edges as though cut with a knife, was seen in the intima; it was situated at the distal end of the solid organizing clot, i.e. at the junction of the ascending and transverse arches of the aorta. The dissecting mass of fluid blood extended to the aortic bifurcation. Distal to the slit in the intima wall the dissecting blood was dark and fluid; it could be pressed back through the slit. The aortic lumen was reduced to the size of a crow quill.

Heart. The heart was not enlarged. The coronary arteries were not involved in the aneurysm. Dr. Discombe stated that atheromatous plaques did not involve the mouths of the coronaries but were present along their lengths. There was no evidence of any coronary infarction. Terminal focal necrosis of a marked degree was present. It is possible that in the intact organ the tumour formed by the extravasated blood could have pressed on the coronary arteries although it did not directly involve them. This pressure would have interfered more with the left coronary and the anterior descending branch. Myocardium, normal macroscopically. A minimal quantity of clear pericardial fluid present. Surfaces normal. Valves normal. Aorta, no atheroma, intima healthy.

Lungs both oedematous. Liver congested; stomach congested slightly; otherwise no abnormality of the gut. 
Microscopically the heart muscle showed focal necrosis. The affected fibres were swollen and had lost their transverse striation and were more deeply eosinophilic than normal. Nuclei had disappeared and there were small numbers of polymorphs infiltrating the necrotic areas and an increase in epimysium cells. Dr. Discombe stated that the focal necrosis in the heart was most remarkable.

\section{Discussion}

There would thus appear to be no clear correlation between the post-mortem findings and the electrocardiographic changes. In neither case was there any evidence of occlusion or gross narrowing or infarction of the coronary circulation. In Case 1, both aneurysms were situated in the descending aorta. It was impossible to determine from the post-mortem reports of either case whether the presence of the dissecting aneurysms could have displaced or twisted the heart in such a way as to interfere with the coronary flow, but the radiological evidence in Case 2 did not support this hypothesis. In each case the cardiogram was very suggestive of posterior coronary infarction: in Case 1 there were changes in the ten days interval between the first and second tracings that strongly favoured a coronary occlusion; in Case 2 the bundle branch tracing that developed may have been a manifestation of the dying heart, since it was present on the day the patient died, but the previous curve showing S-T depression was taken two days before the patient died.

Unfortunately few electrocardiograms have been studied in dissecting aneurysm of the aorta because the patient so frequently dies before one can be taken. In 19 cases studied by Glendy, Castleman, and White (1937), only 2 had cardiograms taken; one of these was normal and the other showed changes suggestive of posterior coronary infarction, but in this instance it was found post-mortem that the aneurysm involved the mouths of the coronary arteries. This was not so in our two cases.

If the changes were due to the great lowering of blood pressure only (Katz, 1941), they should have been present in the cardiogram taken twelve hours after the second severe attack, when the blood pressure was at its lowest: but they were not present. The fibrous patches in the left ventricle in Case 1 were seen on section to be acellular and, therefore, of considerable standing; but in Case 2 the myocardial necrosis may have been significant. If these three possible causes are ruled out, it is difficult to explain the cardiographic changes.

In Case 1, the first attack of pain radiating to the back probably occurred at the time of formation of the upper aneurysm; the second, with characteristic tearing pain, persistent pain in the back, and subsequent dysphagia can be well correlated with the anatomical findings of the lower aneurysm of the thoracic aorta. It was this clinical picture that supported the correct diagnosis after the second attack, especially in view of the persistent pain in the back, an unusual symptom in coronary thrombosis. This case is also atypical in the site and multiplicity of its aneurysms.

The pathological findings in Case 1 strongly suggest that the aneurysms were preceded by hæmatomas produced by rupture of vasa vasorum into a media deficient in elastic fibres. A greatly increased vascularity of the wall of atheromatous vessels with a tendency to intramural hæmorrhage has been well described by Winternitz, Thomas, and LeCompte (1938). The majority of dissecting aneurysms arise in the ascending aorta and, in the absence of local atheroma, upon a basis of cystic medial necrosis coupled with hypertension; it does thus appear that in the descending aorta atheroma, by its associated increased mural vascularity, may play an important if indirect part in the pathogenesis of medial hæmatomas. In addition, advanced atheroma leads to pressure atrophy of the media, and finally may also determine the site of primary intimal rupture.

\section{Summary AND CONClusions}

The most striking feature, and one not previously described, is the misleading influence of the electrocardiogram in the diagnosis of these two cases of dissecting aneurysm. The changes in it, when associated with the rest of the clinical picture, were sufficiently typical of myocardial infarction to mislead attention from the correct diagnosis. Thus the assumption that such changes are absent in dissecting aneurysm may be false. 
The most important points in the differential diagnosis would seem to be as follows. The pain in both cases was referred to the back to a considerable extent, this pain was periodic and extended over a period of as long as 15 weeks in Case 2, with periods of remission. Absence of shortness of breath in an ambulatory patient would also be an important point. Evidence of mediastinal mechanical change should also arouse suspicion of a dissecting aneurysm. The numbness in the left arm and the lump in the throat in Case 2, and the dysphagia in Case 1, all bring out this point. The severity of the pain is such that few conditions other than coronary infarction are likely to be suggested. A pain of similar severity may occur in acute pancreatitis, but here it is the lower part of the back rather than the interscapular area that is the site of the pain.

The post-mortem investigations and notes in Case 1 were the work of Dr. I. Doniach of the British Postgraduate Medical School, Hammersmith; those of Case 2 were the work of Dr. George Discombe of St. Bartholomew's Hospital.

We are grateful to them for permission to publish these; and express our thanks to them for their help, and also to Dr. McMichael of the British Postgraduate Medical School for his kind co-operation in Case 1.

\section{REFERENCES}

Glendy, R. E., Castleman, B., and White, P. D. (1937). Amer. Heart J., 13, 129.

Katz, L. N. (1941). “ "Electrocardiography,” Philadelphia, pp. 162, 251.

Master, A. M. Dacks, Kalter, H. H., and Jaffe, H. L. Amer. Heart J. (1937), 14, 297.

Winternitz, M. C., Thomas, R. M., and LeCompte, P. M. (1938). “"The Biology of Arteriosclerosis," C. Thomas, Springfield, Ill., U.S.A., p. 87. 